LUNG TRANSPLANTATION

\title{
Pepsin like activity in bronchoalveolar lavage fluid is suggestive of gastric aspiration in lung allografts
}

\author{
C Ward, I A Forrest, I A Brownlee, G E Johnson, D M Murphy, J P Pearson, J H Dark, \\ P A Corris
}

See end of article for authors' affiliations

Correspondence to: Dr C Ward, Applied Immunobiology and Transplantation Research Group, Freeman Hospital and University of

Newcastle upon Tyne,

Newcastle upon Tyne NE7 7DN, UK; chris.ward@ncl. ac.uk

Received 20 October 2004 Accepted 30 June 2005

Published Online First

29 July 2005
Background: A biologically plausible link between gastro-oesophageal reflux (GOR), aspiration, and lung allograft dysfunction has been suggested, but there is no systematic evidence indicating the presence of gastric contents in the lung. We have tested the hypothesis that pepsin, as a marker of aspiration, is detectable in bronchoalveolar lavage (BAL) fluid of allograft recipients who had not reported symptoms of GOR.

Methods: Standardised $3 \times 60 \mathrm{ml}$ surveillance BAL fluid samples from 13 chronologically sequential stable lung allograft recipients without chronic rejection (10 patients treated with a prophylactic proton pump inhibitor) were studied. Lavage supernatants were assayed by an ELISA based on a monospecific goat antibody for pepsin/pepsinogen. Pepsin levels were compared with those from four normal volunteer controls.

Results: Pepsin levels were measurable in all allograft recipients, in keeping with gastric aspiration (median $109 \mathrm{ng} / \mathrm{ml}$ (range 35-1375)). In the control group the pepsin levels were below the limit of detection. Treatment with a proton pump inhibitor was not correlated with pepsin levels. There was no correlation between BAL fluid neutrophils and pepsin levels.

Conclusion: These data demonstrate lung epithelial lining fluid concentrations of pepsin in lung allograft recipients which are much higher than blood reference levels, with no detectable pepsin in controls. This provides direct evidence of gastric aspiration, which is potentially injurious to the allograft.
$\mathrm{H}$ uman lung transplantation is a well accepted therapeutic option for selected patients with advanced cardiopulmonary disease, but long term survival is limited by the development of obliterative bronchiolitis, the physiological hallmark of which is the bronchiolitis obliterans syndrome. ${ }^{1}$ The pathophysiology of obliterative bronchiolitis is poorly understood, but it is increasingly recognised to represent immunological and non-immunological mechanisms and an aberrant response to injury. ${ }^{2}$

Gastro-oesophageal reflux (GOR) has been implicated as a possible cause of non-immunological allograft injury. Allograft recipients have a number of risk factors for GOR. Lung allograft surgery causes significant damage to vagal innervation of the gastrointestinal tract and the immunosuppressant drugs cyclosporin and tacrolimus reduce gastric motility. ${ }^{4}$ In addition, cough reflexes and mucociliary clearance, the normal defence mechanisms against aspiration, are attenuated. ${ }^{5}$ All the above make reflux more likely, which is why many allograft recipients are given prophylactic acid suppression treatment.

Despite a high clinical suspicion regarding GOR in lung allografts, the literature is small and largely retrospective. However, formal oesophageal pH studies, when carried out, do indicate that GOR may be a significant problem in lung allografts and fundoplication surgery is associated with improved allograft function. ${ }^{6}$

We are unaware of any literature to date indicating gastric aspiration into the lung, and we have therefore tested the hypothesis that pepsin-as a marker of aspiration-is detectable in the lungs of allograft recipients who do not present with obvious symptoms of GOR.

\section{METHODS}

The study was approved by the local research ethics committees for Newcastle and North Tyneside, with separate applications for prospective studies in lung allografts and normal volunteer controls.

Following informed consent, 13 chronologically sequential unselected subjects undergoing either routine or symptom driven transbronchial biopsy (TBB) and bronchoalveolar lavage (BAL) were recruited (table 1), with the research sample intercalated within this procedure. Research samples were taken at least 1 month after any preceding bronchoscopic procedure and in the absence of any clinical evidence of prior microaspiration. All patients were receiving a standard long term maintenance regimen of immunosuppressive therapy comprising cyclosporin, azathioprine and prednisolone. The patients were not formally investigated for GOR, but did not report symptoms suggestive of GOR. In particular, there were no reports of heartburn, stomach ache, sour taste in the mouth, or pain on swallowing. Ten patients were treated with a prophylactic proton pump inhibitor, which is a common empirical treatment in this patient population.

Four normal non-smoking controls (one woman, median age 39, range 32-46) were recruited from volunteer hospital staff for a research BAL. These subjects were recruited 9 months after the transplant patients, as soon as full ethical approval had been gained for bronchoscopic investigations in normal volunteers.

\section{Bronchoscopy, BAL, and TBB}

Bronchoscopy was carried out in accordance with published guidelines. $^{7}$ Subjects were premedicated with intravenous midazolam. 4\% lignocaine was applied topically to the nose, pharynx, and larynx and below the cords in $1 \mathrm{ml}$ aliquots, as required, up to a maximum dose of $8 \mathrm{mg} / \mathrm{kg}$ body weight.

Abbreviations: BAL, bronchoalveolar lavage; GOR, gastrooesophageal reflux; TBB, transbronchial biopsy 
Table 1 Summary of patient demographic data, BAL and pathological rejection assessments

\begin{tabular}{|c|c|c|c|c|c|c|c|c|c|c|c|c|}
\hline $\begin{array}{l}\text { Subject } \\
\text { no }\end{array}$ & Age & Diagnosis & $\begin{array}{l}\text { Months after } \\
\text { transplant }\end{array}$ & $\begin{array}{l}\text { BAL return } \\
\text { (ml) }\end{array}$ & $\begin{array}{l}\text { Cell count } \\
\left(\times 10^{4} / \mathrm{ml}\right)\end{array}$ & $\begin{array}{l}\text { PMN } \\
(\%)\end{array}$ & $\begin{array}{l}\text { AM } \\
(\%)\end{array}$ & $\begin{array}{l}\text { Lymph } \\
\text { (\%) }\end{array}$ & Microbiology & Biopsy & $\mathrm{PPI} / \mathrm{H}_{2}$ & $\begin{array}{l}\text { Pepsin } \\
\text { (ng/ml) }\end{array}$ \\
\hline 1 & 19 & $\mathrm{CF}$ & 3 & 70 & 36 & 0.2 & 99.6 & 0.2 & Negative & $a 2 / b 1$ & Yes & 81 \\
\hline 2 & 45 & Bronchiectasis & 6 & 95 & 67.2 & 0.2 & 96.4 & 3.4 & Negative & $\mathrm{a} 0 / \mathrm{b} 1$ & Yes & 60 \\
\hline 3 & 25 & PPH & 2.5 & 100 & 24.3 & 1.0 & 98.8 & 0.2 & Negative & $a 2 / 3 b 1$ & Yes & 172 \\
\hline 4 & 25 & OB & 3 & 100 & 34.3 & 3.4 & 96.2 & 0.2 & Negative & $a 1 / b x$ & Yes & 68 \\
\hline 5 & 20 & $\mathrm{CF}$ & 0.25 & 55 & 56.5 & 35.6 & 61.0 & 3.0 & Negative & $a 2 / b x$ & No & 129 \\
\hline 6 & 41 & AlAT & 2.5 & 85 & 22.8 & 7.4 & 86.4 & 5.0 & Negative & $a 2 / b 0$ & No & 50 \\
\hline 7 & 44 & LAM & 6 & 100 & 11 & 1.0 & 94.6 & 4.4 & Negative & $\mathrm{al} / \mathrm{bl}$ & Yes & 34 \\
\hline 8 & 44 & VSD-EISEN & 87 & 95 & 2.6 & 1.4 & 93.0 & 5.6 & Aspergillus & $\mathrm{aO} / \mathrm{b} 0$ & Yes & 67 \\
\hline 9 & 38 & CF & 6 & 80 & 4.7 & 4.6 & 75.8 & 18.4 & Klebsiella & $\mathrm{al} / \mathrm{bl}$ & Yes & 107 \\
\hline 10 & 62 & LAM & 12 & 90 & 39.9 & 2.0 & 94.4 & 3.6 & Negative & $a 0 / b x$ & No & 1375 \\
\hline 11 & 39 & Bronchiectasis & 3 & 75 & 9.6 & 8.0 & 76.0 & 15.8 & Negative & $\mathrm{a} 0 / \mathrm{b} 0$ & Yes & 225 \\
\hline 12 & 47 & AlAT & 2 & 75 & 22.6 & 5.6 & 94.2 & 0.2 & Negative & $a 2 / b 0$ & Yes & 1200 \\
\hline 13 & 21 & $\mathrm{CF}$ & 12 & 95 & 8.5 & 1.0 & 98.2 & 0.6 & Penicillium & $\mathrm{aO} / \mathrm{b} 0$ & Yes & 237 \\
\hline
\end{tabular}

$\mathrm{CF}$, cystic fibrosis; PPH, primary pulmonary hypertension; $\mathrm{OB}$, obliterative bronchiolitis (patient had a second lung transplant due to failure of the first); $\mathrm{Al} A \mathrm{~T}$, $\alpha_{1}$ antitrypsin deficiency; LAM, lymphangiomyomatosis; VSD-EISEN, Eisenmenger's syndrome; PMN, neutrophils; AM, alveolar macrophages; Lymph, lymphocytes; Biopsy, pathological assessment for rejection according to International Society for Heart and Lung Transplantation criteria: a $=$ acute rejection $\leqslant a 1$ nonsignificant, $b=$ airway assessment, $a x b x=$ no material for assessment; $\mathrm{PPI} / \mathrm{H}_{2}$, prophylactic treatment with proton pump inhibitor or $\mathrm{H}_{2}$ receptor antagonist.

Bronchoscopy was carried out with patients in a semireclined position.

Bronchoalveolar lavage was standardised to a $3 \times 60 \mathrm{ml}$ procedure with oxygen saturation routinely measured during the procedure. The BAL fluid sample was split and assessed for clinical microbiology and differential cell counts on Giemsa stained cytocentrifuge preparations. Cell free BAL supernatants were prepared by centrifugation (10 minutes, $1500 \mathrm{rpm}, 10$ minutes ), aliquots snap frozen by immersion in liquid $\mathrm{N}_{2}$, and stored at $-80^{\circ} \mathrm{C}$ prior to ELISA.

Transbronchial biopsies were obtained from allograft patients only.

\section{Pepsin/pepsinogen ELISA}

A locally developed ELISA was performed using $100 \mu \mathrm{l}$ of unconcentrated BAL supernatants. The assay, based on a monospecific antibody to porcine pepsin, measured both pepsin and total pepsinogens, referred to henceforth as "pepsin", with a lower limit of detection of $<1 \mathrm{ng} / \mathrm{ml} .{ }^{8}{ }^{9}$ All assays were performed by one individual and the coefficient of variation for the assay was $13 \%$. Serum reference levels for pepsin are $49.8-86.6 \mu \mathrm{g} / \mathrm{l}){ }^{8}$ The ELISA on the samples from normal subjects were performed 9 months after the transplant patients.

\section{Processing of TBB samples}

Five to seven TBB samples were taken at each allograft bronchoscopy, fixed in 10\% formalin, embedded in paraffin, and stained with haematoxylin and eosin to assess acute or chronic rejection according to standard criteria. ${ }^{10}$

\section{Statistical analysis}

Non-parametric methods were used throughout using Minitab statistical software. The median pepsin levels in allograft recipients were compared with those in control subjects by the Mann-Whitney $U$ test (two tailed).

\section{RESULTS}

Patient demographic data, BAL and pathological rejection assessments are summarised in table 1. Five of the 13 subjects had clinically significant mild to moderate (a2) acute rejection, but all were free from long term irreversible loss of lung function.

\section{BAL fluid data}

The median BAL return was $90 \mathrm{ml}$ (range 55-100) in allograft recipients and $80 \mathrm{ml}$ (range 55-90) in controls, indicating technically satisfactory procedures. As in our

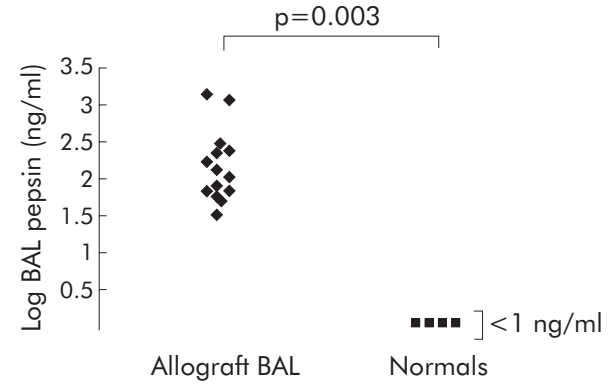

Figure 1 BAL fluid pepsin levels in allograft recipients and controls.

previously published data on allograft patients, the percentage of neutrophils in the BAL fluid of allograft recipients was variable (median 2.0\% (range 0.2-35.6)) and higher than our normal range $(1.6 \%$ (range $0-2), p=0.03) .{ }^{11}$

\section{BAL fluid pepsin levels}

Pepsin levels were measurable in all BAL fluid samples from allograft recipients (fig 1), suggesting gastric aspiration (median $109 \mathrm{ng} / \mathrm{ml}$ (range 35-1375)). In the control group pepsin levels were below the limit of detection $(<\mathrm{l} \mathrm{ng} / \mathrm{ml})$. Treatment with a maintenance dose of proton pump inhibitor did not correlate with pepsin levels. There were no correlations between BAL neutrophils, acute rejection, and pepsin levels.

\section{DISCUSSION}

Limited previous reports, largely retrospective but some with formal objective oesophageal $\mathrm{pH}$ monitoring, have suggested that GOR is a significant problem in lung allograft recipients, ${ }^{6}$ and treatment of GOR has been cited as a new therapeutic option to treat patients with the bronchiolitis obliterans syndrome. ${ }^{12}$

In this study we have shown that high and variable levels of pepsin are detectable in BAL fluid of allograft recipients, with no pepsin detected in normal control BAL fluid samples. To our knowledge, this is the first systematic direct evidence of gastric aspiration into lung allografts. This may be a continuing and cumulative potential injury to allografts, and we provide mechanistic support for this contention.

Absolute determination of the dilution of the pericellular epithelial lining fluid (ELF) sampled by BAL is not possible, ${ }^{13}$ but estimations are practicable, based on the morphometric data of Weibel (cited by Widdicombe ${ }^{14}$ ). These considerations suggest that our BAL procedure represents a dilution of 
approximately 1 in 200 of the ELF sampled, with our present data consistent with ELF concentrations of pepsin 10-10 times higher than serum reference levels. ${ }^{8}$ In contrast, our published data on BAL fluid levels of albumin in allografts are consistent with ELF levels substantially lower than those found in serum. ${ }^{15}$ Overall, our data indicate a gastric source of the pepsin detected.

Pepsin is a proteolytic enzyme, active at acidic $\mathrm{pH}$. There are no data of which we are aware regarding the $\mathrm{pH}$ of allograft ELF, but acidic breath condensate is increasingly reported as a marker of inflammation in asthma, chronic obstructive pulmonary disease, bronchiectasis, cystic fibrosis, and following cardiothoracic surgery. ${ }^{16}$ These $\mathrm{pH}$ levels are consistent with potential proteolytic activity for pepsin. Aspiration of gastric contents into the lung would be anticipated to cause epithelial damage in allografts, stimulation of cytokine production, and an airway inflammatory/ remodelling response, potentially contributing to irreversible loss of allograft function and eventual failure. ${ }^{12}$

It was noteworthy that most of the patients we studied were being treated with a prophylactic proton pump inhibitor at a low maintenance dose. This reflects widespread empirical use in allograft recipients in view of concurrent oral corticosteroid use and their role in patients with cystic fibrosis to prevent pancreatic enzyme supplement degradation. Such medication would be expected to suppress symptoms associated with GOR caused by acid, but a potential concern highlighted by our study is that "clinically occult" aspiration of other gastric contents would still be possible.

Our study, though novel, is preliminary and our control information is limited. However, we specifically adopted a rigorous approach to this by recruiting normal volunteers, and no pepsin was detected in these controls. Our results therefore indicate the presence of unexpectedly high, potentially deleterious levels of pepsin in lung allografts. This may be significant, irrespective of aetiology, with lung allografts singularly vulnerable to injury. ${ }^{12}$ Longitudinal studies are now required to assess whether the presence of BAL pepsin and other markers of GOR are related to long term allograft failure and chronic rejection, and such techniques may be broadly useful in studying other patients with GOR who develop lung disease.

\section{Authors' affiliations}

C Ward, I A Forrest, G E Johnson, D M Murphy, J H Dark, P A Corris, Applied Immunobiology and Transplantation Research Group, Freeman Hospital and University of Newcastle upon Tyne, UK

I A Brownlee, J P Pearson, School of Cell and Molecular Biosciences, Freeman Hospital and University of Newcastle upon Tyne, UK

This study was funded by the Freeman Hospital and University trustees, the European Respiratory Society, and the Medical Research Council

Competing interests: none declared

\section{REFERENCES}

1 Estenne M, Hertz MI. Bronchiolitis obliterans after human lung transplantation. Am J Respir Crit Care Med 2002;166:440-4.

2 Gourishankar SHP. Late deterioration of organ transplants: a problem in injury and homeostasis. Curr Opin Immunology 2002;14:576-83.

3 Reid KR, McKenzie FN, Menkis AH, et al. Importance of chronic aspiration in recipients of heart-lung transplants. Lancet 1990;336:206-8.

4 Maes BD, Vanwalleghem J, Kuypers D, et al. Differences in gastric motor activity in renal transplant recipients treated with $\mathrm{FK}-506$ versus cyclosporine. Transplantation 1999;68:1482-5.

5 Veale D, Glasper PN, Gascoigne A, et al. Ciliary beat frequency in transplanted lungs. Thorax 1993;48:629-31.

6 Davis RD Jr, Lau CL, Eubanks S, et al. Improved lung allograft function after fundoplication in patients with gastroesophageal reflux disease undergoing lung transplantation. J Thorac Cardiovasc Surg 2003;125:533-42.

7 British Thoracic Society. Guidelines on diagnostic flexible bronchoscopy. Thorax 2001;56(Suppl I):i1-21

8 Tasker A, Dettmar PW, Panetti M, et al. Reflux of gastric juice and glue ear in children. Lancet 2002;359:493

9 Tasker A, Dettmar PW, Panetti M, et al. Is gastric reflux a cause of otitis media with effusion in children? Laryngoscope 2002;112:1930-4.

10 Yousem SA, Berry GJ, Cagle PT, et al. Revision of the 1990 working formulation for the classification of pulmonary allograft rejection: Lung Rejection Study Group. J Heart Lung Transplant 1996;15:1-15.

11 Ward C, Snell GI, Zheng L, et al. Endobronchial biopsy and bronchoalveolar lavage in stable lung transplant recipients and chronic rejection. Am J Respir Crit Care Med 1998;158:84-91.

12 Verleden GM, Dupont $\sqcup$, Van Raemdonck DE. Is it bronchiolitis obliterans syndrome or is it chronic rejection: a reappraisal? Eur Respir J 2005;25:221-4.

13 Ward C, Thien F, Secombe J, et al. Bronchoalveolar lavage fluid urea as a measure of pulmonary permeability in healthy smokers. Eur Respir $J$ 2000;15:285-90.

14 Widdicombe JH. Volume of airway surface liquid in health and disease. Am J Respir Crit Care Med 2002;165:1566.

15 Ward C, Walters EH, Zheng L, et al. Increased soluble CD1 4 in bronchoalveolar lavage fluid of stable lung transplant recipients. Eur Respir J 2002;19:472-8.

16 Moloney ED, Mumby SE, Gajdocsi R, et al. Exhaled breath condensate detects markers of pulmonary inflammation after cardiothoracic surgery. Am J Respir Crit Care Med 2004; 169:64-9. 